\title{
IPTEKS PENINGKATAN PENDAPATAN ASLI DAERAH (PAD) BADAN PENGELOLA PAJAK DAN RETRIBUSI DAERAH KOTA MANADO
}

\author{
Angelia Natashia Martina Mewo ${ }^{1}$, Meily Yoke Betsy Kalalo ${ }^{2}$ \\ ${ }^{1,2}$ Jurusan Akuntansi, Fakultas Ekonomi dan Bisnis, Universitas Sam Ratulangi, Kampus Unsrat, Sulawesi Utara, \\ 95115, Indonesia
}

Email: angeliamewo1@gmail.com

\begin{abstract}
Regional tax is the price paid for the area being developed by the region and for the region. Regional tax realization is very influential on regional revenue (PAD). The purpose of this study is to look at tax revenues in the city in this case the Tax Management and Retribution Agency of the City of Manado. The method used is descriptive method because this study consists of explanatory words. This study gets tangible results from knowing 2016 until 2017 there has been an increase. However, there are still several types of local taxes that have decreased. Therefore, the city of Manado or BP2RD must have more or more obligations that still do not have the awareness to guide taxes, so that tax revenues / realization in the city of Manado will continue to increase.
\end{abstract}

Keywords : regional tax, collection, local revenue

\section{PENDAHULUAN}

Untuk membangun suatu daerah tentunya tidak dapat dipisahkan dengan dana. Sumber dana suatu daerah ialah PAD. Pendapatan Asli daerah merupakan Pendapatan pemerintah dari hasil-hasil daerah yang tercantum dalam peraturan perundang-undangan dan digunakan untuk membiayai setiap kebutuhan suatu daerah. Pendapatan asli daerah didapatkan dari hasil pajak daerah, hasil retribusi daerah, pinjaman daerah, dan pendapatan daerah lain yang sah. Pendapatan asli daerah digunakan untuk Anggaran Pendapatan dan Belanja Daerah (APBD). Menurut UU No 34 Tahun 2000 pajak daerah diartikan sebagai kewajiban yang wajib dibayarkan oleh orang pribadi atau badan kepada daerah tanpa balasan yang akan membiayai penyelenggaraan Pemerintah Daerah dan pembangunan daerah.

Menurut Resmi (2012) ada 3 jenis pajak yang dikelompokan menurut golongan, menurut sifat, dan menurut lembaga pemungutannya:

1. Pajak Menurut Golongan : (a) Pajak Langsung, dan (b) Pajak Tidak Langsung.

2. Pajak Menurut Sifat : (a) Pajak Subjektif, dan (b) Pajak Objektif.

3. Pajak menurut lembaga pemungutannya : (a) Pajak Pusat/Negara, dan (b) Pajak Daerah Pajak daerah sangat berpengaruh dalam pembangunan suatu daerah. Jika pendapatan pajak meningkat, maka pendapatan asli daerah pun akan meningkat. Namun, masih banyak masyarakat atau wajib pajak yang belum sadar akan pentingnya pajak dalam suatu daerah. Banyak faktor yang membuat wajib pajak tidak menyetorkan kewajiban tersebut, seperti: masih kurangnya pengetahuan tentang pentingnya pajak dan yang terutama wajib pajak merasa keberatan dengan tarif pajak yang di tetapkan oleh pemerintah. Maka dari itu pemerintah dalam hal ini Badan pengelola Pajak Dan Retribusi Daerah Kota Manado harus lebih jeli lagi untuk memberikan pemahaman kepada wajib pajak atau masyarakat betapa pentingnya pajak untuk kemajuan daerah tersebut.

\section{TINJAUAN PUSTAKA}

Pajak Daerah. Menurut Undang-Undang No. 28 Pasal 1 Tahun 2009. Pajak Daerah adalah kewajiban kepada daerah yang bersifat memaksa yang tertuliskan dalam UU, dengan 
tidak mendapatkan balasan dari pemerintah dan digunakan untuk menunjang seluruh kebutuhan daerah dan kesejahteraan masyarakat. Menurut Smeets dalam Waluyo, (2011) pajak merupakan Prestasi yang terutang kepada pemerintah melalui peraturan UU dan bersifat dipaksakan, dan digunakan untuk membiayai pengeluaran kebutuhan daerah. Pajak diartikan sebagai iuran rakyat kepada negara yang dapat dipaksakan, dan dibayarkan oleh wajib pajak membayarnya menurut peraturan-peraturan Undang-Undang. Menurut peraturan pemerintah Republik Indonesia No. 55 Tahun 2016, jenis pajak daerah yang dipungut oleh pemerintah daerah dan yang ditetapkan oleh kepala daerah adalah : (a) Pajak Reklame; (b) Pajak Air Tanah; dan (c) PBB P2. Dan pembayaran pajak yang dihitung oleh wajib pajak itu sendiri dengan tarif pajak yang di berikan oleh pemerintah adalah : Pajak Hotel, Pajak Restoran, Pajak Hiburan, Pajak Penerangan Jalan, Pajak Mineral buka Logam dan Batuan, Pajak Parkir, Pajak Sarang Burung Wallet, dan BPHTB.

Pendapatan Asli Daerah. Menurut Halim (2011), Pendapatan Asli Daerah (PAD) merupakan seluruh pendapatan daerah yang bersumber dari ekonomi asli daerah. Pendapatan Asli Daerah bersumber dari empat jenis pendapatan, yaitu pajak daerah, retribusi daerah, hasil perusahaan milik daerah dan hasil pengelolaan kekayaan milik daerah yang dipisahkan, lain-lain Pendapatan Asli Daerah yang sah. Menurut Nurcholis (2007 : 182) pendapatan asli daerah adalah pendapatan yang diperoleh daerah dari penerimaan pajak daerah, retribusi daerah, laba perusahaan daerah dan lain-lain yang sah. Pada dasarnya pengertian Pendapatan asli daerah sama, yaitu pendapatan yang berasal dari daerah yang sumbernya berasal dari Pajak Daerah, Retribusi Daerah, Pengelolaan Kekayaan daerah dan pendapatan lain-lain yang didapatkan oleh suatu daerah. Pendapatan asli daerah digunakan untuk membiayai setiap keperluan umum suatu daerah, jadi jika peneriaam/realisasi pajak terjadi kenaikan,maka pendapatan asli daerah (PAD) pun juga akan meningkat.

Pemungutan Pajak Daerah. Pemungutan Pajak adalah suatu mekanisme yang memberikan penugasan dan tanggunjawab kepada pihak ketiga untuk melakukan pemungutan atas pajak yang terutang. Terdapat 4 macam tarif pajak menurut Mardiasmo (2009:9), yaitu : tarif sebanding/proporsional, tarif tetap, tarif progresif, dan tarif degresif. Sistem pemungutan pajak di Indonesia terbagi menjadi 3 sistem, yaitu :

1. Self Assessment System, yang berarti wajib pajak merupakan pihak yang akan menghitung, membayar dan melaporkan pajak di loket atau tempat pembayaran pajak.

2. Official Assessment System, yang berarti pajak terutang baru ada setelah dikeluarkannya surat ketetapan pajak oleh fiskus.

3. Withholding System merupakan system pemungutan pajak yang langsung dipotong misalnya lewat gaji.

Pemungutan pajak harus memenuhi beberapa syarat, yakni : (1) syarat keadilan yaitu pemungutan pajak haruslah merata berdasarkan undang-undang. (2) syarat yuridis, yaitu pajak trlah diatur dengan berbagai undang-undang (3) syarat ekonomis, maksudnya pemungutan pajak tidak boleh mengganggu kelancaran kegiatan produksi dan perdagangan sehingga tidak menimbulkan kelesuan perekonomian masyarakat, (4) Syarat finansial yaitu biaya pemungutan pajak tidak lebih besar dari hasil pemungutan pajak dan biaya-biaya yang dikeluarkan, (5) syarat keserdahaan bermaksud agar dapat dipahami oleh wajib pajak dan wajib pajak atau masyarakat mudah untuk menghitung sendiri dan mendorong wajib pajak dalam membayarkan kewajiban pajaknya.

Menurut Undang Undang Dasar 1945 pasal 23a, bertuliskan bahwa Pajak dan pungutan lain bersifat memaksa yang digunakan untuk keperluan negara yang diatur dengan undangundang. 


\section{METODE PENELITIAN}

\subsection{Metode Penerapan Ipteks}

Metode IPTEKS yang digunakan yaitu dengan melakukan studi kasus atas hasil pemungutan pajak yang telah dilakukan oleh Badan Pengelola Pajak dan Retribusi Kota Manado tahun 2016 dan tahun 2017 apakah terjadi peningkatan atau penurunan.

\subsection{Teknik Penerapan Ipteks}

Teknik Ipteks yang diterapkan yaitu dengan melakukan perbandingan antara tahun 2016 dengan tahun 2017 dari data yang diterima dari BP2RD.

\section{PEMBAHASAN}

\subsection{Profil Objek Penelitian}

Badan Pengelola Pajak dan Retribusi Daerah Kota Manado dibentuk berdasarkan Perda Kota Manado No. 2 Tahun 2011 tentang pembentukan Organisasi dinas-dinas daerah Kota. Badan Pengelolah Pajak Dan Retribusi Daerah Kota Manado mempunyai tugas yaitu untuk melaksanakan kewenangan otonomi Daerah Kota dalam rangka pelaksanaan tugas Desentralisasi.

\subsection{Pembahasan}

Badan Pengelola Pajak dan Retribusi Daerah Kota Manado setiap hari menerima pembayaran pajak dan mencatatnya untuk dijadikan laporan tahunan kepada pemerintah pusat sebagai laporan penerimaan pajak yang nantinya akan dimasukan ke dalam kas Pendapatan Asli Daerah. Tabel 1 menunjukan bahwa pada tahun 2016 pemerintah kota manado menerima realisasi pajak sebesar 165.894.109.055 dan pada tahun 2017 tercatat penerimaan/realisasi pajak sebesar 192.714842.821. tentunya dari tahun 2016 sampai 2017 pemerintah kota manado menerima realilisasi pajak lebih tinggi dari tahun sebelumnya yakni tahun 2016.

Tabel 1. Hasil perbandingan penerimaan pajak daerah (dalam Rp.)

\begin{tabular}{lrrrc}
\hline \multicolumn{1}{c}{ Jenis Penerimaan } & \multicolumn{1}{c}{$\mathbf{2 0 1 6}$} & \multicolumn{1}{c}{$\mathbf{2 0 1 7}$} & \multicolumn{1}{c}{ SELISIH } & KET \\
\hline Pajak Hotel & 25.425 .453 .862 & 30.499 .296 .864 & 5.073 .843 .002 & Naik \\
Pajak Restoran & 60.607 .630 .932 & 71.905 .821 .095 & 11.298 .190 .163 & Naik \\
Pajak Hiburan & 11.012 .273 .849 & 11.556 .376 .025 & 554.102 .536 & Naik \\
Pajak Reklame & 8.922 .985 .528 & 7.842 .596 .559 & 1.080 .388 .969 & Turun \\
Pajak Parkir & 8.429 .890 .942 & 10.345 .892 .836 & 1.916 .001 .894 & Naik \\
Pajak Air Tanah & 1.056 .966 .368 & 835.608 .882 & 221.387 .486 & Turun \\
Pajak Sarang Burung Walet & 3.760 .000 & 4.960 .000 & 1.200 .000 & Naik \\
Pajak Mineral Bukan Logam dan & - & - & - & - \\
Batuan & & & & \\
BPHTB & & & & \\
Pajak Bumi dan Bangunan P2 & 28.630 .670 .885 & 52.729 .778 .691 & 24.099 .107 .806 & Naik \\
Pajak Penerangan Jalan (PPJ) PLN & 27.710 .018 .490 & 27.771 .345 .028 & 61.326 .538 & Naik \\
Total & 50.435 .147 .574 & 59.724 .290 .560 & 9.289 .115 .986 & Naik \\
\hline Sumber: Rincian Penerimaan Pendapatan Daerah TA 2016-2017 BP2RD & &
\end{tabular}

Sumber : Rincian Penerimaan Pendapatan Daerah T.A 2016-2017 BP2RD

Pajak Hotel. Realisasi/penerimaan Pajak Hotel dari bulan januari sampai desember pada tahun 2016 sebesar 25.425.453.862 sedangkan pada tahun 2017 di bulan yang sama realisasi pajak hotel sebesar 30.499.296.864. dari tahun 2016 dan tahun 2017 terdapat selisih kenaikan yang begitu besar yaitu 5.073.843.002.

Pajak Restoran. Realisasi/penerimaan Pajak Restoran merupakan realisasi pajak paling besar yang ada di daerah. Realisasi Pajak Restoran pada bulan januari sampai pada bulan desember tahun 2016 sebesar 60.607.630.932 dan pada tahun 2017 pada bulan januari sampai desember terjadi kenaikan sebesar 71.905.821.095. Maka selisih realisasi pajak Restoran dari 
Tahun 2016-2016 sebesar 11.298.190.163. ini merupakan suatu keberhasilan dari pemerintah kota manado, akan tetapi masih harus di tingkatkan kembali.

Pajak Hiburan. Realisasi atau penerimaan Pajak Hiburan pada tahun 2016 di bulan januari hingga desember sebesar 11.012.273.849 dan pada tahun 2017 di bulan yang sama sebesar 11.556.376.025. Penerimaan pajak hiburan pun terjadi kenaikan dengan selisih yang dimiliki 554.102.536.

Pajak Reklame. Berbeda dengan realisasi pajak-pajak diatas, Reliasasi/penerimaan pajak reklame pada tahun 2017 dbulan januari hingga desember terjadi penurunan di bandingkan dengan tahun sebelumnya. Realisasi pajak reklame pada tahun 2016 bulan januari sampai desember sebesar 8.922.985.528 sedangkan pada tahun 2017 sebesar 7.842.596.559. dapat kita lihat selisih penurunan yang dimiliki adalah 1.080.388.969.

Pajak Parkir. Realisasi/penerimaan Pajak Parkir dari bulan januari sampai desember pada tahun 2016 sebesar 8.429.890.942 sedangkan pada tahun 2017 di bulan yang sama realisasi pajak Parkir sebesar 10.345.892.836 dari tahun 2016 dan tahun 2017 terdapat selisih kenaikan yang begitu besar yaitu 1.916.001.894.

Pajak Air Tanah. Realisasi/penerimaan Pajak Air Tanah dari tahun 2016 ke tahun 2017 terjadi penurunan. Pada tahun 2017 pemerintah kota manado dalam hal ini Badan Pengelola Pajak dan Retribusi Daerah hanya menerima realisasi Pajak Air Tanah sebesar 835.608.882 sedangkan pada tahun sebelumnya yaitu tahun 2016 pemerintah menerima realisasi sebesar 1.056.966.368. maka selisih yang dimiliki adalah sebesar 221.387.486.

Pajak Sarang Burung Wallet. Realisasi/penerimaan Pajak Sarang Burung Wallet pada bulan januari sampai pada bulan desember tahun 2016 sebesar 3.760 .000 dan pada tahun bulan januari hingga desember tahun 2017 terjadi kenaikan sebesar 4.960.000. Maka selisih realisasi pajak sarang burung wallet dari Tahun 2016-2017 sebesar 1.200.000.

Pajak Mineral Bukan Logam dan Batuan. Badan Pengelola Pajak dan Retribusi daerah kota Manado pada bulan januari hingga desember 2016 tidak menerima realisasi pajak mineral bukan logam dan batuan. Begitupun dengan tahun 2017 BP2RD masih belum menerima reliasasi pajak mineral bukan logam dan batuan.

BPHTB. BPHTB merupakan kepanjangan dari Bea Perolehan Hak atas Tanah dan Bangunan. Pemungutan BPHTB pada tahun 2016 dari bulan Januari hingga bulan Desember adalah 28.630.670.885 dan mengalami kenaikan pada tahun 2017 di bulan yang sama sebesar 24.099.107.806. sehingga di tahun 2017 pendapatan BPHTB mencapai 52.729.778.691.

Pajak Bumi dan Bangunan P2. Penerimaan pajak Bumi dan Bangunan Perkotaan dan Pedesaan di tahun 2017 mengalami kenaikan hingga penerimaan di tahun 2017 mencapai 27.771.345.028 sedangkan pada tahun 2016 hanya mencapai 27.710.018.490.

Pajak Penerangan Jalan. Realisasi/penerimaan Pajak Penerangan Jalan pada bulan januari hingga bulan desember tahun 2016-2017 terjadi kenaikan. Pada tahun 2017 realisasi pajak penerangan jalan tercatat sebesar 59.724.290.560 Berbeda dengan tahun 2016 realisasi pajak penerangan jalan hanya sebesar 50.435.147.574. Penerimaan/Realisasi Pajak di kota manado terjadi peningkatan dari target yang di tetapkan pada tahun 2017 penerimaan pajak mengalami kenaikan dan melebihi target yang sudah tetapkan oleh pemerintah. Target realisasi pajak yang ditetapkan pemerintah kota manado sebesar 227.900.000.000 sedangkan yang diterima oleh BP2RD sebesar 273.215.966.540. Namun, masih banyak wajib-wajib pajak yang menghindar dari pembayaran pajak. Oleh sebab itu pemerintah kota manado dalam hal ini BP2RD selalu berupaya untuk dapat menjangkau wajib pajak yang masih belum memiliki kesadaran akan pembayaran pajak dengan memberikan sosialisasi kepada wajib pajak-wajib pajak betapa pentingnya dana pendapatan asli daerah untuk menunjang pembangunan yang ada. Selain itu BP2RD juga sering melakukan pengawasan terhadap wajib pajak yang sering memanipulasi data pendapatan yang diterima setiap bulan dengan turun langsung ke tempat usaha dan melihat langsung pendapatan yang diterima. 


\section{KESIMPULAN DAN SARAN}

\subsection{Kesimpulan}

Pemungutan pajak daerah pada tahun 2016 sampai tahun 2017 terjadi peningkatan yang signifikan. Sehingga pendapatan asli daerah pun ikut meningkat. Namun masih ada beberapa jenis pajak daerah yang malah mengalami penurunan.

\subsection{Saran}

1. Pemerintah harus lebih jeli terhadap penerimaan pajak setiap tahunnya. Karena masih ada jenis pajak daerah yang mengalami penurunan penerimaan pajak, agar di tahun-tahun berikutnya penerimaan pajak dapat lebih meningkat.

2. Pemerintah harus lebih tegas dalam hal memberikan sanksi kepada oknum wajib pajak yang masih belum membayarkan pajak agar setiap wajib pajak yang ada akan merasa bertanggung jawab dengan kewajiban pajak.

\section{DAFTAR PUSTAKA}

Dinas Pendapatan Daerah Kota Manado. 2015. Buku Selayang Pandang Dinas Pendapatan Kota Manado.

Mardiasmo. 2009. Perpajakan Edisi Revisi Tahun 2009. Yogyakarta: Andi Offset.

Nurcholis, Hanif. 2007. Teori dan Praktik Pemerintahan dan Otonomi Daerah. Jakarta : Grasindo.

Pemerintah Repoblik Indonesia. 2000. Undang-Undang Pemerintah No.34 Tahun 2000. Pajak Daerah. Jakarta

Pemerintah Republik Indonesia. 2004. Undang-undang Pemerintah No. 33 Tahun 2004. Tentang Pertimbangan Keuangan Antara Pusat dan Daerah. Jakarta

Pemerintah Kota Manado.2011. Peraturan Kota Manado No. 02 Tahun 2011. Pembentukan Dinas-dinas Daerah Kota Manado

Pemerintah Republik Indonesia.2016. undang-undang pemerintah No.55 tahun 2016. Tentang ketentuan umum dan tata cara pemungutan pajak daerah. Jakarta

Pemerintah Republik Indonesia. 1945. Undang-undang Dasar Pasal 23A.

Resmi, Siti. 2012. Perpajakan Teori dan Kasus Jilid Edisi 6 Buku 1. Jakarta: Salemba Empat.

Waluyo. 2011. Perpajakan Indonesia edisi 10. Jakarta: Salemba Empat

Watulingas, C., Kindangen, P., dan Engka, D (2018). Pengaruh pendapatan asli daerah terhadap pertumbuhan ekonomi di Provinsi Sulawesi Utara. Jurnal pembangunan ekonomi dan keuangan daerah. 19(7), 5.

Yulaika, R (2014). Pengaruh sistem pemungutan pajak dan tarif pajak terhadap efektifitas pajak reklame bagi toko di kabupaten Ngawi. Jurnal Ilmiah STKIP PGRI Ngawi. 13(1). 3. 